OPEN ACCESS

Edited by:

Lino Nobili,

University of Genova, Italy

Reviewed by:

Giancarlo Vanini,

University of Michigan, United States

Axel Steiger,

Max-Planck-Institut für Psychiatrie,

Germany

Sergio Garbarino

University of Genoa, Italy

${ }^{*}$ Correspondence:

Jonas Vinstrup

jonasvinstrup@gmail.com

Specialty section:

This article was submitted to

Sleep and Chronobiology,

a section of the journal

Frontiers in Neurology

Received: 15 August 2018

Accepted: 29 October 2018

Published: 21 November 2018

Citation:

Vinstrup J, Jakobsen MD,

Calatayud J, Jay K and Andersen LL

(2018) Association of Stress and Musculoskeletal Pain With Poor Sleep:

Cross-Sectional Study Among 3,600 Hospital Workers.

Front. Neurol. 9:968.

doi: 10.3389/fneur.2018.00968

\section{Association of Stress and Musculoskeletal Pain With Poor Sleep: Cross-Sectional Study Among 3,600 Hospital Workers}

\author{
Jonas Vinstrup ${ }^{1,2 *}$, Markus Due Jakobsen ${ }^{1}$, Joaquin Calatayud ${ }^{1,3}$, Kenneth Jay $^{4}$ and \\ Lars Louis Andersen ${ }^{1,2}$ \\ ${ }^{1}$ National Research Centre for the Working Environment, Copenhagen, Denmark, ${ }^{2}$ Sport Sciences, Department of Health \\ Science and Technology, Aalborg University, Aalborg, Denmark, ${ }^{3}$ Exercise Intervention for Health Research Group, \\ Department of Physiotherapy, University of Valencia, Valencia, Spain, ${ }^{4}$ The Carrick Institute for Graduate studies, Institute of \\ Clinical Neuroscience and Rehabilitation, Cape Canaveral, FL, United States
}

Background: While acute stress and pain are part of our inherent survival mechanisms, persistent stress and pain can negatively impact health and well-being. This may also lead to poor sleep and thus a lack of recovery. This study investigated the influence of stress and musculoskeletal pain on sleep quality.

Methods: A total of 3,593 Danish hospital workers replied to a questionnaire about work and health. Pain intensity was evaluated using subjective values as an average of 9 body parts. Stress was assessed using the full version of Cohen's Perceived Stress scale. Sleep quality was rated using 3 questions on sleep characteristics. Associations between stress and pain (mutually adjusted predictors) and sleep (outcome) were modeled using binary logistic regression controlling for gender, age, education, BMI and smoking.

Results: The risk ratio of moderate stress (compared to no/low stress) on poor sleep was 1.27 (Cl 1.26-1.29), whereas the risk ratio of high stress on poor sleep was $1.87(\mathrm{Cl}$ 1.83-1.91). Similarly, for pain, the risk ratio of moderate pain (compared to no/low pain) on poor sleep was $1.18(95 \% \mathrm{Cl} 1.16-1.19)$, whereas the risk ratio of a high pain score on poor sleep was 1.48 (95\% Cl 1.44-1.52).

Conclusion: This study demonstrates that both stress and musculoskeletal pain are associated with poor sleep among hospital workers. Hospital management should consider implementing strategies for preventing stress and musculoskeletal pain to improve the overall health and workability among hospital workers.

Keywords: health care personnel, sleep, stress, pain, working environment 


\section{INTRODUCTION}

Sleep serves vital biological functions including, but not limited to; physiological processes, learning, memory, health and cognition $(1,2)$. Consequently, sleep deprivation yields numerous detrimental effects on the organism and even mild sleep deprivation negatively affects pain sensitivity in healthy adults $(3,4)$. For example, sleep deprivation has been shown to be an important risk factor of decreased immunity (5), to increase the pro-inflammatory cytokine response (6), to increase the risk of obesity, dementia and diabetes (7-10) and to compromise mood, performance and alertness $(11,12)$. Finally, both long $(>9 \mathrm{~h})$ and short $(<6 \mathrm{~h})$ sleep durations are associated with increased risk of all-cause mortality (13, 14).

Especially the association between sleep and pain has been highlighted in the literature (15-20). Considering the biopsychosocial approach to pain (21-23), it seems logical that this relationship exists. However, the directionality of the sleep/pain association is not entirely clear and has been a progressively growing area of research: Early longitudinal studies were reviewed by Smith and Haythornthwaite in 2004, where 5 of 6 and 4 of 6 studies reported evidence for a pain sleep and a sleep pain directionality, respectively (20). Since then, more than twice as many prospective studies investigating the directionality of the sleep/pain association have emerged, and the collected evidence from more recent research utilizing longitudinal and micro-longitudinal research designs points toward a slightly greater effect of sleep on pain than pain on sleep (17). However, regardless of directionality, it is abundantly clear that sleep and pain strongly influence one another among the general population. What is less clear is the strength of this association within specific groups of the working population. Hospital workers constitute a population with a well-known high prevalence of musculoskeletal disorders (MSD). For instance, more than $36 \%$ of Danish nurses experience pain several times during a normal work week, and the annual prevalence of low back pain is $55 \%$ among this subgroup of the working population $(24,25)$. Given the stressful working environment and irregular working hours, it is not unlikely that sleep deprivation and increased sensitivity to pain will result in serious consequences when working with patients. Additionally, as is the case with sleep and pain, psychological stress often co-occurs with sleep deprivation (26). In fact, nurses have a high risk of developing emotional distress related to job stress; such as burnout, anxiety and depression, which will have detrimental effects on the physical and mental wellbeing $(27,28)$.

Therefore, this study aims to quantify the association between subjective measures of sleep and perceived pain intensity on a large population of hospital workers. Aside from being novel in investigating the sleep/pain relationship among this specific population of the workforce, we include correlations between sleep and stress as a secondary outcome. Although other potential risk factors-such as the musculoskeletal load during daily patient handlings (29)-still need to be investigated in more detail, the associations between vital lifestyle factors presented herein should be used as guidelines to direct future efforts with the goal of improving the overall wellbeing and working environment among hospital workers.

\section{METHODS}

\section{Study Design and Participants}

This study is a cross-sectional questionnaire survey among 3,593 hospital workers from Danish hospitals, with 2,098 working as nurses. The survey seeks to elucidate the effect of workenvironmental factors as well as different types of patient transfers and the use of assistive devices on the prevalence of back injury and low back pain, and includes 1-year follow-up, biweekly short questionnaires as well has technical measurements of muscle activity and body position during patient handlings (29).

The current study presents baseline analyses on the associations between stress/sleep and pain/sleep. Data was collected during the summer 2017 from hospitals in northern Denmark. As a way to achieve a generalized understanding of the health and working environment in Danish hospitals, the only inclusion criterion was that all participants were working at hospital. Following this, we did therefore not divide participants into subgroups based on occupation. Table 1 describes participant demographics and mean stress scores rated on Cohen's Perceived Stress Scale.

\section{Outcome Variable}

\section{Sleep}

With the goal of achieving a broad indicator of overall sleep quality, 3 questions adapted from the Bergen Insomnia Scale regarding initiating \& maintaining sleep, ease of awakening and overall tiredness during daytime, were asked:

How often during the previous 4 weeks have you...

a)... awoken during the night and having trouble going back to sleep?

b) ... been feeling exhausted when waking up?

c) ... been feeling tired during the day?

These questions have been used in the 2012, 2014, and 2016 rounds of the Danish Work Environment Cohort Study (DWECS), with questionnaires sent out to more than 50,000 people in the Danish workforce during each round. By using data

TABLE 1 | Demographics, $N=3$ 3,593. CPS; Cohen's perceived stress.

\begin{tabular}{llll}
\hline & Mean & (SD) & $\%$ \\
\hline Age $(\mathrm{y})$ & 45.8 & $(11.4)$ & \\
$\mathrm{BMI}\left(\mathrm{kg} / \mathrm{m}^{2}\right)$ & 25.1 & $(4.7)$ & \\
CPS $(0-40)$ & 12.5 & $(5.8)$ & \\
SEX & & 86 \\
Women & & & 14 \\
Men & & & \\
SMOKING & & & 9 \\
Yes & & & 91 \\
No & &
\end{tabular}


previous published on this cohort $(n=7,883)$ we conducted a Pearson's correlation between the 3 questions used in this study and all 6 questions of the Bergen Insomnia Scale (PCC 0.94). Furthermore, we also performed an analysis on the correlation between the questions used herein and the remaining 3 questions of the scale (PCC 0.78) (30). Because of the high correlations presented we are confident in utilizing this simplified version as an indication of sleep quality.

The questions were rated on a 5-point Likert scale with items consisting of "never," "rarely," "sometimes," "often," and "always." Based on the 3 questions the scores were then converted to a scale ranging from $0-100$, with $0-50$ and 50-100 indicative of poor and good sleep, respectively. This was done by allocating each item of the Likert scale a numeric score; ranging from 0 ("always") to 100 ("never"), with 25-point intervals between scores.

Table 2 shows the distribution of poor and good sleep. Because not all participants replied to all questions, the exact number of replies varies.

\section{Predictor Variables \\ Pain}

As part of the questionnaire, the participants were asked to rate their average pain intensity within the previous 4 weeks for 9 body regions (neck, shoulder, upper back, lower back, elbows, hands/wrists, hips, knees and feet/ankles), on a visual numeric scale ranging from 0 to 10 . The values for the 9 body parts were then averaged to represent a global pain score for the individual. Values 0 to 1 were characterized as "no/low pain", whereas values 1.001 to 4 and 4.001 to 10 were characterized as "moderate pain" and "high pain," respectively. Table 2 shows the distribution of no/low, moderate and high pain scores among the participants.

The numerical rating scale (NRS) is a simple technique for measuring a subjective experience. The NRS is valid, reliable and appropriate for use in clinical practices, and has been widely used to subjectively measure pain intensity. The NRS shows higher compliance rates, better responsiveness as well as higher sensitivity and applicability in comparison to the visual analog scale (VAS) $(31,32)$. Therefore, in this questionnaire study we used a modified NRS/VAS scale; consisting of a horizontally drawn line with numerical indications from 0 to 10 . The participants answered by marking one of the numerical values on the line for each of the 9 body regions.

TABLE 2 | Distribution of sleep, pain and stress scores.

\begin{tabular}{lll}
\hline Variable & N & $\%$ \\
\hline Poor sleep & 1,919 & 57 \\
Good sleep & 1,432 & 43 \\
No/low stress & 1,212 & 37 \\
Moderate stress & 1,803 & 54 \\
High stress & 301 & 9 \\
No/low pain & 1,565 & 47 \\
Moderate pain & 1,568 & 48 \\
High pain & 175 & 5
\end{tabular}

\section{Cohen's Perceived Stress}

The perceived stress scale by Cohen (referred to as Cohen's Perceived Stress Scale, CPSS) is a widely used measurement of subjective stress levels (36). Answers to questions on the scale are rated on a 5-point Likert scale, identical to the one mentioned previously to quantify sleep quality (ranging from "never" to "always"). Scores are then summed; with higher scores indicate a higher level of perceived stress. To ensure classification of the reference group, i.e., "no/low pain," the following divisions were used: $0-10,10.001-20$, and 20.001-40 for low, moderate and high stress, respectively.

For the general population, scores of $\sim 13$ and above 20 indicate normative values and high stress, respectively. Table 2 shows the distribution of no/low, moderate and high stress scores among the participants.

\section{Statistics}

SAS version 9.4 was used for all analyses. Associations between stress and pain (mutually adjusted predictors) and sleep (outcome) were modeled using binary logistic regression (Proc Genmod) controlling for age, sex (male/female), education, BMI (mass $/ \mathrm{h}^{2}$ ) and smoking (yes/no).

Values are presented as Risk Ratios (RR) and 95\% confidence intervals (CI).

\section{RESULTS}

A total of 3,593 hospital workers participated in this questionnaire survey. The number of missing answers on questions related to sleep, stress and pain was 249, 284, and 292, respectively. Table 2 shows the distribution of answers as absolute numbers (N) and percentages (\%).

Among this population, the risk ratio of moderate stress (compared to no/low stress) on poor sleep was 1.27 (95\% CI 1.261.29 ), whereas the risk ratio of high stress on poor sleep was 1.87 (95\% CI 1.83-1.91). Similarly, for pain, the risk ratio of moderate pain (compared to no/low pain) on poor sleep was 1.18 (CI 1.161.19), whereas the risk ratio of a high pain score on poor sleep was 1.48 (CI 1.44-1.52) (Table 3).

\section{DISCUSSION}

This study shows that stress and pain are associated with increased risk of poor sleep in a population of 3,593 Danish

TABLE 3 | Risk ratio (RR) of stress and pain on risk of poor sleep.

\begin{tabular}{lllll}
\hline Variable & & RR & CI & \\
\hline Stress & Moderate vs. low & $\mathbf{1 . 2 7}$ & 1.26 & 1.29 \\
& High vs. low & $\mathbf{1 . 8 7}$ & 1.83 & 1.91 \\
Pain & Moderate vs. low & $\mathbf{1 . 1 8}$ & 1.16 & 1.19 \\
& High vs. low & $\mathbf{1 . 4 8}$ & 1.44 & 1.52 \\
\hline
\end{tabular}

Cl; 95\% confidence interval. Adjusted for gender, age, education, BMI, and smoking; RR, Risk Ratio. 
hospital workers. Our results illustrate that both stress and pain influence the risk of poor sleep in a dose-response manner.

Interestingly, the association between stress and sleep was stronger than that between pain and sleep. High levels of perceived stress seem to be detrimental to the health of the individual not only as a consequence of the stress response itself, but also via an increased risk of poor sleep: Following only one night of sleep deprivation, participants from a recent wellcontrolled experimental study experienced increased cortisol levels as well as increased levels of subjective stress (26). Following this, prolonged high levels of stress may therefore negatively influence the workability of this population (33), as the effects of stress and poor sleep are likely to be additive over time.

Similar to the nature of pain and despite prevailing views in modern society, stress cannot be considered inherently bad. Acute episodes of stress, with the accompanying release of catecholamines and cortisol, serve evolutionary important functions in regards to the "fight or flight"-response. Cortisol, a potent and longer-lasting chemical, is produced in a daily pattern by the adrenal gland to deal with stressors (34). Under normal circumstances the body benefits from and is more than capable of handling acute increases in stress hormones. However, as with pain, when the stress-response becomes persistent without credible external cues, issues related to health and wellbeing are likely to develop as prolonged exposure to high cortisol levels leads to a number of unfortunate biological events such as low libido, temporary infertility, inflammation, weight gain, appetite changes and obesity $(34,35)$.

As a valid indicator of perceived stress, normative values [mean (SD)] for Cohen's Perceived Stress Scale are 12.1 (5.9) for men and $13.7(6.6)$ for women $(36,37)$. Therefore, a score of approximately 13 should be considered average in the working population. With a perceived stress score of 12.5 (5.8) observed in the present study, this population of hospital workers does not constitute a unique situation but is likely to represent a trend in the general working population. Considering the strong doseresponse relationship between stress and sleep, it seems vital to focus on one or both of these lifestyle factors as they are likely to influence each other bi-directionally. Following this, even slight improvements in stress and/or sleep parameters are likely to influence work ability and sickness absence positively among hospital workers (38).

Similar to the acute stress response, we require both sleep and pain for survival. However, persistent impairments to systems regulating sleep and pain will result in broad and pronounced negative impacts on health and well-being. Pain is a strong behavioral motivator that serves to protect the individual from harm. As a classic example, the danger signal that is sensed by the brain when accidentally touching a hot stove will cause a reflective withdrawal of the hand to avoid permanent tissue damage. This example serves as a reminder that pain itself is not to be considered a negative phenomenon, as it serves a vital evolutionary purpose. However, when the brain continues to produce pain even when the tissue damage has long since healed and the survival of the organism is no longer threatened, persistent pain-likely characterized and influenced by neuro inflammation and central sensitization-can develop
(39). Within the population of Danish hospital workersespecially among nurses-it is likely that the high prevalence of musculoskeletal pain is an indicator of a system experiencing continuous threat due to various job-related stressors; e.g., mechanical overload, understaffed and odd working hours that might influence sleep negatively. This adds evidence of perceived threat to the individual and hence increase the likelihood of experiencing pain $(24,40)$.

In the current study, the participants were asked to rate their levels of perceived stress, pain and sleep quality during the previous 4 weeks. More than half of the participants rated their sleep as being poor, as well as their pain- and stress levels to be either moderate or high. Similar to the situation in other regions of the world regarding the working environment among hospital workers $(27,28)$, these numbers serve to highlight the notion that the wellbeing as well as the working environment of Danish hospital workers, especially among nurses, could be improved.

Whereas the stress response needs to be persistent over time in order to elicit detrimental effects on health and wellbeing, only minor disturbances in sleep are needed in order to experience negative consequences. Indeed, increased pain sensitivity after only 1 night of partial $(4 \mathrm{~h})$ sleep loss has been observed (3). Extending these findings, 1 night of total sleep deprivation has been shown to induce a state of generalized hyperalgesia and mood changes associated with increased anxiety levels (4). Luckily, these changes in pain sensitivity can readily be reversed with extended time in bed (41), which highlights one of the possible actions to easily counteract the consequences of sleep loss and poor sleep in general.

Another potent way to increase sleep quality and duration is to improve sleep hygiene; e.g., ensure a completely dark, cool and dimmed-light bedroom. Limiting the amount of blue light (i.e., light from electronic equipment) in the hours prior to bedtime has been shown to positively affect various sleep parameters including evening sleepiness, melatonin secretion, circadian rhythm as well as next-morning alertness (42). Furthermore, limiting light- and screen exposure prior to sleep is not only an easy and effective way to prevent sleep deprivation, it also has the potential to influence sleep related issues on a national scale: In a study involving 1,508 participants, 9 out of 10 reported using technological devices within $1 \mathrm{~h}$ before bedtime (43), indicating a great potential for improving sleep hygiene among the general population. In the context of hospital workers, especially during evening- and nightshifts, it is highly likely that the exposure to blue light will affect sleep and circadian rhythm negatively.

Taken together, it seems evident that stress, sleep and pain likely have an additive impact on the working environment of hospital workers. Furthermore, although not assessed in the current study, relatively small changes are likely to influence the health and well-being of this population by decreasing job-related stressors, and hence perceived threat.

\section{STRENGTHS AND LIMITATIONS}

The limitations of this study include the fact that we are unable to establish directionality between the associations between stress, pain and sleep. However, based on the cited literature and the clear dose-response relationships between these, they all very 
likely influence one another. Following this, because a broad range of factors are likely to influence overall sleep quality in an individual, the limitations of utilizing a simplified version of the Bergen Insomnia Scale should be noted and any practical implementation strategy should reflect this notion. Furthermore, the results cannot be generalized as they are specific to the working population of hospital workers; the majority being nurses. Clear strengths of the present study are the high number of participants and the establishment of a subjective global pain score based on 9 body regions. Therefore, rather than being specific to one type of pain or one body part, the values presented in this study represent an overall perceived pain score in a subpopulation of the workforce.

\section{CONCLUSION}

Clear dose-response relationships exist between perceived stress and poor sleep as well as between pain intensity and poor sleep among hospital workers. The long-term consequences on health and workability of these associations need to be investigated in detail, but for now they should serve as indications as to where

\section{REFERENCES}

1. Cirelli C, Tononi G. Is sleep essential? PLoS Biol. (2008) 6:e216. doi: 10.1371/journal.pbio.0060216

2. Dattilo M, Antunes HKM, Medeiros A, Mônico Neto M, Souza HS, Tufik $\mathrm{S}$, et al. Sleep and muscle recovery: endocrinological and molecular basis for a new and promising hypothesis. Med Hypotheses (2011) 77:220-2. doi: 10.1016/j.mehy.2011.04.017

3. Roehrs T, Roth T. Sleep and pain: interaction of two vital functions. Semin Neurol. (2005) 25:106-16. doi: 10.1055/s-2005-867079

4. Schuh-Hofer S, Wodarski R, Pfau DB, Caspani O, Magerl W, Kennedy JD, et al. One night of total sleep deprivation promotes a state of generalized hyperalgesia: a surrogate pain model to study the relationship of insomnia and pain. Pain (2013) 154:1613-21. doi: 10.1016/j.pain.2013.04.046

5. Cohen S, Doyle WJ, Alper CM, Janicki-Deverts D, Turner RB. Sleep habits and susceptibility to the common cold. Arch Intern Med. (2009) 169:62-7. doi: 10.1001/archinternmed.2008.505

6. Irwin MR, Wang M, Campomayor CO, Collado-Hidalgo A, Cole S. Sleep deprivation and activation of morning levels of cellular and genomic markers of inflammation. Arch Intern Med. (2006) 166:1756-62. doi: 10.1001/archinte.166.16.1756

7. Greer SM, Goldstein AN, Walker MP. The impact of sleep deprivation on food desire in the human brain. Nat Commun. (2013) 4:2259. doi: $10.1038 /$ ncomms3259

8. Knutson KL, Spiegel K, Penev P, Van Cauter E. The metabolic consequences of sleep deprivation. Sleep Med Rev. (2007) 11:163-78. doi: 10.1016/j.smrv.2007.01.002

9. Shi L, Chen SJ, Ma MY, Bao YP, Han Y, Wang YM, et al. Sleep disturbances increase the risk of dementia: a systematic review and meta-analysis. Sleep Med Rev. (2017) 40:4-16. doi: 10.1016/j.smrv.2017.06.010

10. Spiegel K, Leproult R, L'Hermite-Balériaux M, Copinschi G, Penev PD, Van Cauter E. Leptin levels are dependent on sleep duration: relationships with sympathovagal balance, carbohydrate regulation, cortisol, and thyrotropin. $J$ Clin Endocrinol Metab. (2004) 89:5762-71. doi: 10.1210/jc.2004-1003

11. Belenky G, Wesensten NJ, Thorne DR, Thomas ML, Sing HC, Redmond DP, et al. Patterns of performance degradation and restoration during sleep restriction and subsequent recovery: a sleep dose-response study. J Sleep Res. (2003) 12:1-12. doi: 10.1046/j.1365-2869.2003.00337.x hospitals could intervene in order to improve the local working environment.

\section{ETHICS STATEMENT}

In accordance with Danish laws, ethical approval is not required when performing a questionnaire-study. The study is approved by the Danish Data Protection Agency (j. nr. 2015-41-4232).

\section{AUTHOR CONTRIBUTIONS}

JV, MJ, JC, KJ, and LA contributed to the design of the study as well as analysis and interpretation of the results. JV drafted the manuscript while MJ, JC, KJ, and LA revised it critically before approving the content for publication.

\section{ACKNOWLEDGMENTS}

Author LA obtained a grant from the Danish Working Environment Research Fund for this study (grant number AMFF 26-2015-09).

12. Bonnet MH, Arand DL. We are chronically sleep deprived. Sleep (1995) 18:908-11. doi: 10.1093/sleep/18.10.908

13. Cappuccio FP, D’Elia L, Strazzullo P, Miller MA. Sleep duration and all-cause mortality: a systematic review and meta-analysis of prospective studies. Sleep (2010) 33:585-92. doi: 10.1093/sleep/33.5.585

14. da Silva AA, de Mello RGB, Schaan CW, Fuchs FD, Redline S, Fuchs SC. Sleep duration and mortality in the elderly: a systematic review with meta-analysis. BMJ Open (2016) 6:e008119. doi: 10.1136/bmjopen-2015-008119

15. Choy EHS. The role of sleep in pain and fibromyalgia. Nat Rev Rheumatol. (2015) 11:513-20. doi: 10.1038/nrrheum.2015.56

16. Evans S, Djilas V, Seidman LC, Zeltzer LK, Tsao JCI. Sleep quality, affect, pain, and disability in children with chronic pain: is affect a mediator or moderator? J Pain (2017) 18:1087-95. doi: 10.1016/j.jpain.2017. 04.007

17. Finan PH, Goodin BR, Smith MT. The association of sleep and pain: an update and a path forward. J Pain (2013) 14:1539-52. doi: 10.1016/j.jpain.2013.08.007

18. Kelly GA, Blake C, Power CK, O’Keeffe D, Fullen BM. The association between chronic low back pain and sleep: a systematic review. Clin J Pain (2011) 27:169-81. doi: 10.1097/AJP.0b013e3181f3bdd5

19. Simpson NS, Scott-Sutherland J, Gautam S, Sethna N, Haack M. Chronic exposure to insufficient sleep alters processes of pain habituation and sensitization. Pain (2017) 159:33-40. doi: 10.1097/j.pain.000000000 0001053

20. Smith MT, Haythornthwaite JA. How do sleep disturbance and chronic pain inter-relate? Insights from the longitudinal and cognitivebehavioral clinical trials literature. Sleep Med Rev. (2004) 8:119-32. doi: 10.1016/S1087-0792(03)00044-3

21. Hancock MJ, Maher CG, Laslett M, Hay E, Koes B. Discussion paper: what happened to the "bio" in the bio-psycho-social model of low back pain? Eur Spine J Off Publ Eur Spine Soc Eur Spinal Deform Soc Eur Sect Cerv Spine Res Soc. (2011) 20:2105-10. doi: 10.1007/s00586-011-1886-3

22. Kamper SJ, Apeldoorn AT, Chiarotto A, Smeets RJEM, Ostelo RWJG, Guzman J, et al. Multidisciplinary biopsychosocial rehabilitation for chronic low back pain: cochrane systematic review and meta-analysis. BMJ (2015) 350:h444. doi: 10.1002/14651858.CD000963.pub3

23. Moseley GL, Butler DS. Fifteen years of explaining pain: the past, present, and future. J Pain Off J Am Pain Soc. (2015) 16:807-13. doi: 10.1016/j.jpain.2015.05.005 
24. Davis KG, Kotowski SE. Prevalence of musculoskeletal disorders for nurses in hospitals, long-term care facilities, and home health care: a comprehensive review. Hum Factors (2015) 57:754-92. doi: 10.1177/0018720815581933

25. Møller J, Bach E. Danskernes arbejdsmiljø 2014. Copenhagen: Kbh, Det Nationale Forskningscenter for Arbejdsmiljø (2016).

26. Schwarz J, Gerhardsson A, van Leeuwen W, Lekander M, Ericson M, Fischer $\mathrm{H}$, et al. Does sleep deprivation increase the vulnerability to acute psychosocial stress in young and older adults? Psychoneuroendocrinology (2018) 96:155-65. doi: 10.1016/j.psyneuen.2018.06.003

27. Escribà-Agüir V, Martín-Baena D, Pérez-Hoyos S. Psychosocial work environment and burnout among emergency medical and nursing staff. Int Arch Occup Environ Health (2006) 80:127-33. doi: 10.1007/s00420-006-0110-y

28. Lim J, Bogossian F, Ahern K. Stress and coping in Australian nurses: a systematic review. Int Nurs Rev. (2010) 57:22-31. doi: 10.1111/j.1466-7657.2009.00765.x

29. Vinstrup J, Madeleine P, Jakobsen MD, Jay K, Andersen LL. Patient transfers and risk of back injury: protocol for a prospective cohort study with technical measurements of exposure. JMIR Res Protoc. (2017) 6:e212. doi: 10.2196/resprot.8390

30. Andersen LL, Garde AH. Sleep problems and computer use during work and leisure: Cross-sectional study among 7800 adults. Chronobiol Int. (2015) 32:1367-72. doi: 10.3109/07420528.2015.1095202

31. Hjermstad MJ, Fayers PM, Haugen DF, Caraceni A, Hanks GW, Loge $\mathrm{JH}$, et al. Studies comparing numerical rating scales, verbal rating scales, and visual analogue scales for assessment of pain intensity in adults: a systematic literature review. J Pain Symptom Manage. (2011) 41:1073-93. doi: 10.1016/j.jpainsymman.2010.08.016

32. Williamson A, Hoggart B. Pain: a review of three commonly used pain rating scales. J Clin Nurs. (2005) 14:798-804. doi: 10.1111/j.1365-2702.2005.01121.x

33. Golubic R, Milosevic M, Knezevic B, Mustajbegovic J. Work-related stress, education and work ability among hospital nurses. J Adv Nurs. (2009) 65:2056-66. doi: 10.1111/j.1365-2648.2009.05057.x

34. Sapolsky RM. Why Zebras Don't Get Ulcers: The Acclaimed Guide to Stress, Stress-Related Diseases, and Coping - Now Revised and Updated. New York, NY: Henry Holt and Company (2004).
35. Lundberg U. Stress, subjective and objective health. Int J Soc Welf. (2006) 15:S41-8. doi: 10.1111/j.1468-2397.2006.00443.x

36. Cohen S, Kamarck T, Mermelstein R. A global measure of perceived stress. J Health Soc Behav. (1983) 24:385-96.

37. Cohen S, Janicki-Deverts D, Miller GE. Psychological stress and disease. JAMA (2007) 298:1685-7. doi: 10.1001/jama.298.14.1685

38. Rosekind MR, Gregory KB, Mallis MM, Brandt SL, Seal B, Lerner D. The cost of poor sleep: workplace productivity loss and associated costs. J Occup Environ Med. (2010) 52:91. doi: 10.1097/JOM.0b013e3181c78c30

39. Ji R-R, Nackley A, Huh Y, Terrando N, Maixner W. Neuroinflammation and central sensitization in chronic and widespread pain. Anesthesiology (2018) 129:343-66. doi: 10.1097/ALN.0000000000002130

40. Brodal P. A neurobiologist's attempt to understand persistent pain. Scand J Pain (2017) 15:140-7. doi: 10.1016/j.sjpain.2017.03.001

41. Roehrs TA, Harris E, Randall S, Roth T. Pain sensitivity and recovery from mild chronic sleep loss. Sleep (2012) 35:1667-72. doi: 10.5665/sleep.2240

42. Chang A-M, Aeschbach D, Duffy JF, Czeisler CA. Evening use of light-emitting eReaders negatively affects sleep, circadian timing, and next-morning alertness. Proc Natl Acad Sci USA (2015) 112:1232-7. doi: $10.1073 /$ pnas.1418490112

43. Gradisar M, Wolfson AR, Harvey AG, Hale L, Rosenberg R, Czeisler CA. The sleep and technology use of Americans: findings from the National Sleep Foundation's 2011 Sleep in America poll. J Clin Sleep Med JCSM Off Publ Am Acad Sleep Med. (2013) 9:1291-9. doi: 10.5664/jcsm.3272

Conflict of Interest Statement: The authors declare that the research was conducted in the absence of any commercial or financial relationships that could be construed as a potential conflict of interest.

Copyright (c) 2018 Vinstrup, Jakobsen, Calatayud, Jay and Andersen. This is an open-access article distributed under the terms of the Creative Commons Attribution License (CC BY). The use, distribution or reproduction in other forums is permitted, provided the original author(s) and the copyright owner(s) are credited and that the original publication in this journal is cited, in accordance with accepted academic practice. No use, distribution or reproduction is permitted which does not comply with these terms. 